\section{CONTROL OF ATOMIC ENERGY}

$\mathrm{T}$ HE academic study of nuclear physics has led to the release of nuclear energy and to the atomic bomb. Britain and the United States together agreed to use the new weapon against the cities of Japan. They are now preoccupied with the problem of how to prevent this diabolic agent of destruction from ever again being used, either against themselves or against any other peace-loving nation, while at the same time preserving some opportunity for the development and possible exploitation of its peaceful uses.

The unprecedented rapidity of this translation of an academic discovery into the most powerful agent of military tactics has insured that the drive and interest of scientific men, particularly those engaged in the final stages of its preparation, should be turned naturally to the consideration of the ticklish technical and political problems of its control. Through the public activities of the Committee of Atomic Scientists of the United States, later amalgamated into the Federation of American Scientists, the subject received such wide interest through the Press and radio of the world that the original proposals for legislation in the United States for the control of nuclear energy by a primarily military organisation were defeated. There can be little doubt that the activity of men of science in the United States and the United Kingdom hastened, if it did not initiate, the meeting between Mr. Attlee, Mr. Truman and Mr. Mackenzie King, which originated the proposal that the United Nations Organisation should establish a commission to consider the problem. The early and united stand made by the American scientific workers has affected profoundly all thinking about atomic energy, and the many constructive proposals made by them about international control, and the pre-requisite of free dissemination of scientific information, have reacted strongly on those responsible for the framing of national legislations.

The care with which the State Department of the United States has considered the far-reaching implications of atomic energy is evident from the document before us*. The mode of its preparation is an inter. esting example of the profound differences which are sometimes to be found between the working of democracy in the United States and in Great Britain. In order that the American representative on the Atomic Energy Commission of the United Nations Organisation should be properly briefed, a committee was set up "to study the subject of controls and safeguards necessary to protect this Government, so that the person hereafter selected to represent the United States on the Commission can have the benefit of the study". This committee consisted of Mr. Dean Acheson, Drs. Bush and Conant, Major-General L. R. Groves, who was administratively responsible for the whole atomic bomb project in the United States, and Mr. J. J. MeCloy. At the first meeting in January it was "agreed that it was first essential to have a report prepared analysing and appraising all the relevant facts and formulating proposals". Preparation of this report was entrusted to "men of recognized attainments and varied background, who would be prepared to devote the major part of their time to the matter". This board consisted of Mr. D. E. Lilienthal, chairman of the Tennessee Valley Authority, who acted as

* A Report on the International Control of Atomic Energy. Prepared for the Secretary of State's Committee on Atomic Energy by a Borrd of Consultants, Washington, D.C. Pp. viii +44 . (Washington, D.C.: Government Printing Office ; London: H.M. Stationery Office, 1946.) 1s. net. chairman, Mr. C. I. Barnard, Dr. C. A. Thomas, and Mr. Harry A. Winne, all technical executives of private industrial concerns, and Dr. J. R. Oppenheimer, professor of theoretical physics in the California Institute of Technology, who was in charge of the Los Alamos section of the atomic bomb project. Throughout the report signed by the Board, acknowledgment is made to innumerable scientific and industrial men who were consulted, and whose opinions were available. The result is a report of the highest importance, which may well serve as a model for British efforts to formulate corresponding proposals for consideration by the Atomic Energy Commission of the United Nations Organisation.

It is natural that such proposals should be coloured primarily by the dangers to which the development of methods of mass destruction exposes the United States of America, and it is probable that other countries would give somewhat different emphasis to the issues raised. The primary conception is the separation of the various aspects of atomic energy into processes which are 'dangerous' in that they could be steps in a national move to make atomic weapons, and processes which are 'safe', or which can be carried on with negligible risk that they can be converted quickly to warlike purposes. The 'dangerous' operations are to be the prerogative of the United Nations Organisation, the 'safe' being allowed to individual nations and to industry under proper safeguards. The prime 'dangerous' operations are the mining or acquisition of sources of fissile materials, principally uranium, and the preparation from them of concentrates suitable for the production of bombs. The limited occurrence of rich ores and the size of plant for dealing with low-grade ores, or for separation of isotopes or preparation of plutonium, are factors rendering it comparatively easy to detect evasion of these restrictions. 'Denatured' materials, presumably uranium 235 and plutonium mixed with isotopic material which is difficult to separate without major plant, would be supplied for the exploitation, under licence, of atomic power for peaceful purpose, for the preparation of artificial radioactive 'tracer' elements, for experimental purposes and for the preparation of powerful neutron sources. This 'denatured' material could not be used, on present knowledge, for the preparation of atomic bombs. Any attempt to separate it from the denaturing body would be a serious infringement of regulations to be prepared by the United Nations Organisation.

An important feature of the proposals is that a comparatively few specified operations are to be declared illegal, and infringement of any one of these restrictions would be complete evidence of war-like intent. There would be no necessity to prove that an infringing authority had evil intentions. This would serve greatly to simplify procedure by the United Nations authority, and indeed lifts the basis for international action from the cumbrous sphere of theoretical law to the simple proof of the carrying out. of a physical process.

The interim period before the Atomic Energy Commission of the United Nations Organisation can take over the complete supervision of atomic energy, and during which America continues to possess a complete monopoly of all actual plants capable of preparing atomic bombs, and of the majority of information on technical knowledge, as well as of some strictly scientific but essential information, is the critical period in which the proposals, if implemented, are likely to meet greatest difficulty. The problem 
of reconciling a proper care for the security of the United States with essential handing over of information to the new body is solved in a manner which is eminently reasonable from the American point of view, but which may not seem so free from danger to the U.S.S.R. If other countries are prepared to accept the avowed intention of the United States to preserve a proper regard for the interests of all nations until such time as her trusteeship of what is admittedly an ephemeral possession of a unique weapon can be handed over to the United Nations Organisation, all will be well. The danger lies in international tensions over peace treaties, bases, or economic problems of trade, which might precipitate crises aggravated by the unilateral possession of the new weapon of destruction. From the technical point of view the suggested action seems very reasonable, and the system of control would work if proper provision is made for the fact that new discoveries may alter profoundly the basis of the proposals. There runs through the whole report a spirit of optimism which is highly infectious, and it is necessary to remember that confidence in complete physical understanding and knowledge has often been upset in the past by further scientific investigation. The great weight of technical skill and opinion embodied in the proposals renders it improbable that further knowledge will invalidate them in the near future, but allowance must be made for such an eventuality.

Consideration of these valuable proposals should be tempered by the realization that other countries, which are short of coal and other sources of power, may be more directly interested in the peaceful production of power by atomic methods than is the United States, which is so richly endowed by Nature. The suggestion that the handing over to the United Nations Organisation of information and executive power in atomic energy should take place by stages, and rather slowly, may result in an atomic arms race during the period of trusteeship by the United States. If promptly acted upon, these proposals could save the world. If political dilatoriness and self-seeking lead to stalling tactics and lack of agreement, they may have precisely the opposite results.

\section{L. OLIPhant}

\section{AN ESTIMATE OF THE AGE OF THE EARTH \\ By PROF. ARTHUR HOLMES, F.R.S. \\ Grant Institute of Geology, University of Edinburgh}

$\mathrm{E}$ VER since the publication by Nier and his coworkers $^{1}$ of the relative abundances of the isotopes in twenty-five samples of lead from common lead minerals of various geological ages (Table 1), I have entertained the hope that from these precise data it might be possible to fathom the depths of geological time. The calculations involved are, however, somewhat formidable, and a systematic investigation became possible only recently, with the acquisition of a calculating machine, for which grateful acknowledgment is made to the Moray Endowment Research Fund of the University of Edinburgh. The results have fully justified expectation and indicate that the age of the earth, reckoned from the time when radiogenic lead first began to accumulate in earth-materials, is of the order 3,000 million years.
In his first paper, Nier pointed out that those samples of lead "which contain relatively more $\mathrm{Pb}^{208}$ also contain relatively more $\mathrm{Pb}^{207}$ and $\mathrm{Pb}^{208}$ ". The abundances of these isotopes, listed in Table 1 , are all relative to $\mathrm{Pb}^{204}=1$. Since $\mathrm{Pb}^{204}$ is not generated by any naturally radioactive element, it can be taken as an invariable constituent of the primeval lead occurring in the earth at the time of the earth's origin. Calling the lead with the lowest relative abundances (No. 19) "the least contaminated lead", Nier sug. gested that all the other samples could be regarded as made up of this "least contaminated lead" plus additions of $\mathrm{Pb}^{206}$ and $\mathrm{Pb}^{207}$ generated from uranium, and of $\mathrm{Pb}^{208}$ generated from thorium. The minerals from which the samples of lead were extracted are all essentially free from radioactive elements, and hence the excess isotopes must have been generated before the minerals were formed. This point is, of course, of fundamental importance. It can easily be calculated that if the excess isotopes in the Joplin leads (Nos. 911) had been formed in the ore itself, the necessary amounts of the radioactive elements would have been $6.2 \mathrm{gm}$. U I, $24 \mathrm{gm}$. AcU and $20 \mathrm{gm}$. Th per gm. of galena-impossible amounts, hundreds of millions of times greater than any actual traces that may locally be present. Post-deposition contamination of lead being thus completely ruled out, it follows that before its concentration in ores, the lead must have been TABLE 1. ISOTOPIC ABUNDANCES $\left(\mathrm{Pb}^{304}=1\right.$ ) OF LEAD (NIER et al.)
FROM MINERALS OF VARIOUS AGES.

No. Source of lead, locality and geological age of ore deposit

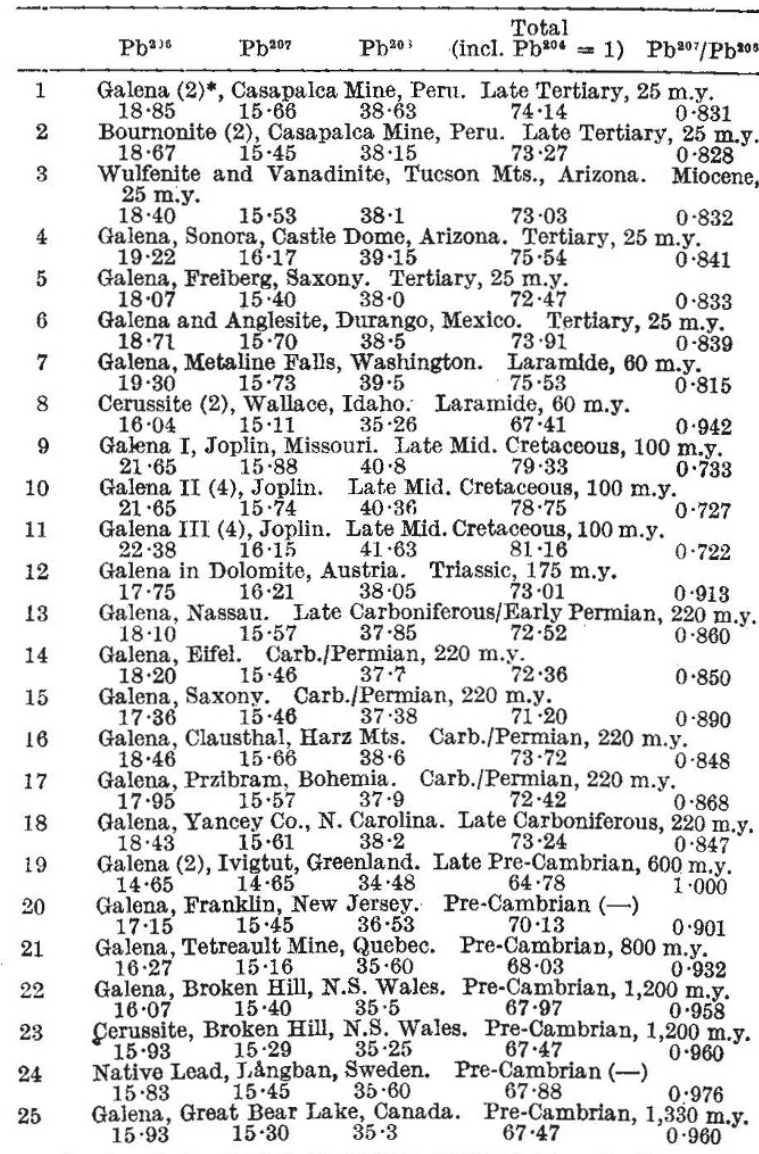

- Numbers in brackets indicate the number of determinations made. In all such cases the results closely agreed and the average figures are those here given. 